Pablo Ortúzar (editor), Subsidiariedad. Más allá del Estado y del mercado (Santiago: Instituto de Estudios de la Sociedad, 2015).

RESEÑA

\title{
SUBSIDIARIEDAD: EL ESLABÓN OLVIDADO
}

\section{Jorge Fábrega}

Universidad Adolfo lbáñez

U $\mathrm{n}$ diagnóstico recorre Chile. Ese diagnóstico es que estamos viviendo una crisis de confianza institucional generalizada que tiene su expresión máxima en la política, pero que cuenta con sus propias versiones en el ámbito de las empresas, las iglesias, los establecimientos educacionales y un largo etcétera. Se ha vuelto rutina que una noticia sobre un abuso o corrupción puntual termina revelando, con el pasar de los meses, grandes arquitecturas institucionales corroídas, tráficos inadmisibles de influencia, ilegales financiamientos de la actividad política, prácticas empresariales antiéticas, etcétera. Nos hemos visto obligados a mirar todo lo que habíamos tirado debajo de la alfombra en el proceso de construir el que, sin lugar a dudas, ha sido el período de mayor desarrollo de la historia del país. Chile es hoy una sociedad más madura, diversa y compleja, pero sigue vistiendo los ropajes de su adolescencia. Y por sus calles y ciudades un nuevo ciudadano, empoderado y bastante individualista, expresa su total sospecha hacia todo lo establecido. La realidad sobre la cual se construye ese diagnóstico es la de un país que ha seguido un "modelo" de desarrollo neoliberal con correcciones importantes (al juzgar de algunos) o más bien tímidas (al juzgar de otros). A grandes rasgos, tal arreglo institucional ha puesto

Jorge Fábrega. Economista y sociólogo de la P. Universidad Católica de Chile. $\mathrm{PhD}$ en políticas públicas de la Universidad de Chicago. Investigador en Datavoz/ Statcom Consultores y docente en la Escuela de Gobierno de la Universidad Adolfo Ibáñez. Email: jorge.fabrega@uai.cl. 
el peso del desarrollo económico y social en iniciativas privadas mayormente desreguladas; y cuando han sido reguladas, los organismos públicos a cargo de tal acción cuentan con atribuciones limitadas o con una total falta de recursos como para pedirles eficacia. En ese marco institucional, se le ha reconocido al Estado un rol activo sólo para suplir la iniciativa privada allí donde ésta no se ha desenvuelto espontáneamente. Ese rol reservado para el Estado en este marco institucional ha recibido el rótulo de "rol subsidiario del Estado", tanto a nivel constitucional como en el debate cotidiano.

Ahora bien, como el diagnóstico es que estamos pasando por una crisis de confianza en las instituciones y la realidad es que vivimos bajo un marco institucional específico (la denominada "economía social de mercado"), es natural esperar que muchos abracen la idea de que la causa de la crisis es ese marco en particular y, por lo tanto, su expectativa es que, una vez desarmado, la crisis será resuelta. Esta intuición ha promovido con fuerza en el debate público un ideario político cuya propuesta esencial es desarticular las lógicas privadas (entendidas como mercado) que están presentes en gran parte de nuestras interacciones e instalar, en su reemplazo, lógicas públicas (entendidas como Estado). Bajo este prisma, si el marco institucional vigente es uno en el que el Estado tiene un rol subsidiario; entonces, el objetivo político - señala el ideario- debe ser acabar con la lógica que subyace a la subsidiariedad. Dicho de otro modo, la crisis que recorre Chile sería la crisis del rol subsidiario del Estado, la del marco institucional que nos ha gobernado durante las últimas décadas. Quizás no haya historia más gráfica de ese ideario político que la evolución de la idea del "no al lucro". Al inicio, la legitimidad del discurso contra el lucro en educación obedecía al hecho que, por ley, las universidades no deben lucrar. No obstante, al cabo de pocos años, el discurso político contra el lucro devino en la idea que debía acabarse con las lógicas del mercado en todo el proceso educativo. El problema dejó de ser la ilegalidad del lucro en educación superior y pasó a ser que el lucro mismo era el causante principal de las inequidades que tiene el sistema educativo chileno desde la educación básica a la educación superior. Por ende, acabar con la crisis de confianza en la institucionalidad educativa implicaba acabar con el rol subsidiario del Estado en educación. 
Es, al menos, curioso que el país de la región con más progreso en las últimas décadas y uno de los más estables de pronto descubra que todo lo obrado ha sido retroceso y, por ende, decida que debe aplicar tabula rasa y partir de nuevo. Pero ha sido la incapacidad de las élites políticas para canalizar las demandas de los movimientos estudiantiles del año 2006, o de las más aún fuertes movilizaciones sociales de 2011, lo que finalmente permitió a ese ideario político abrirse paso y obtener amplios éxitos político-electorales en los últimos años. Tal es así que, al momento que escribo estas líneas, por primera vez desde la recuperación de la democracia en 1990 un signo de interrogación se ha instalado respecto a cuál podría ser el marco institucional en el futuro, no sólo en el sistema educativo sino también en la Constitución, la carta fundamental de nuestra vida en común.

Es en este contexto general que Subsidiariedad. Más allá del Estado y del mercado ${ }^{1}$ es una contribución interesante a un debate nacional sediento de marcos conceptuales desde los cuales pensar el futuro político del país. Organizado en tres bloques de tres capítulos cada uno, cada cual escrito por uno o dos autores, Subsidiariedad rescata la complejidad de un concepto que en la historia chilena reciente ha quedado reducido a su mínima expresión debido a la fuerte influencia que tuvo en su interpretación Jaime Guzmán. En Chile, el principio de subsidiariedad, al ser vinculado a la libertad económica y a la restricción del papel del Estado en la economía fue, en palabras de Hugo Herrera, “... restringido a su faz negativa, negándose al Estado una participación activa en el campo económico, salvo excepcionalmente y sometido a severas restricciones" (103). Se trata de una concepción afín a una visión neoliberal del Estado como la que se impuso política, económica y constitucionalmente en las décadas de 1970 y 1980.

Si bien, el concepto de subsidiariedad tiene efectivamente una dimensión negativa, no se agota en ese aspecto. Como lo recuerdan varios de los autores, la clave del concepto es que reconoce "el carácter eminentemente relacional y comunitario del ser humano" (Alvarado y Galaz, 37), de tal forma que "más que fundarse en una noción negativa

${ }^{1}$ Pablo Ortúzar (editor), Subsidiaridad. Más allá del Estado y del mercado (Santiago: Instituto de Estudios de la Sociedad, 2015). En adelante, este libro se citará, cuando corresponda, especificando el autor del artículo en cuestión y el número de página. 
de libertad, asume una concepción multiforme de la sociedad: la subsidiariedad, en definitiva, consiste en aceptar el carácter complejo de la vida social" (Mansuy, 74). Ello supone reconocer distintas esferas de competencia para las organizaciones y comunidades que las sociedades se dan (agrupaciones intermedias) y que las tornan autónomas ante el Estado; de forma tal que a éste se le exige "subsidiar, no suplir: es decir, ayudar, no sustituir" (Letelier, 122). La subsidiariedad no es el retiro del Estado, tampoco es el asistencialismo del Estado; se trata de ayudar al humano en su desarrollo. Ello implica responsabilidad y solidaridad. Como consecuencia, el principio de subsidiariedad no es simplemente "una regla general, aplicable universalmente y según la cual las situaciones hayan de ser usualmente subsumidas. En cambio, la subsidiariedad, en su sentido originario, es antes un articulador de decisiones que han de estar vinculadas necesariamente a estudios empíricos y a la consideración de los rendimientos reales de las agrupaciones intermedias y del Estado, pues se trata de un principio que es comparativo y concreto" (Herrera, 111). Por lo tanto, el concepto de subsidiariedad no se define ex ante, "no puede comprenderse como un principio mecánico, porque su aplicación exige un conocimiento detallado de las circunstancias" (Mansuy, 75). En suma, al abarcar la relación de las personas no sólo con el Estado o los mercados, el concepto de subsidiariedad es bastante abierto y flexible a diferentes soluciones institucionales y, por ende, tiene razón Matías Petersen cuando pregunta “¿por qué muchos lo interpretan como una simple defensa del 'neoliberalismo'?” (145).

Despojada de sus múltiples sentidos positivos, la subsidiariedad quedó reducida a una consigna antiestatal propia de ciertas formas de liberalismo económico donde el Estado es concebido y construido como un Estado mínimo. Las consecuencias de esta implementación del concepto en Chile no fueron inocuas para el desarrollo del país. Como bien lo indica Hugo Herrera: “... la combinación de subsidiariedad preponderantemente negativa y el severo resguardo de la propiedad individual ha permitido que el poder económico en Chile se vuelva oligopólico a tal punto que casi todo debemos comprarlo en cadenas; además, la ausencia de actores suficientes entorpece la sana competencia y vuelve mucho más fáciles la colusión y los abusos" (Herrera, 105). En otras palabras, toda la capacidad promotora y enriquecedora de las agrupaciones intermedias, que es propia de la concepción subsidiaria del 
Estado, fue primero ignorada y posteriormente olvidada, reduciendo al concepto a su mínima expresión; esto es: tornándolo inútil.

Los autores de Subsidiariedad hacen un excelente trabajo de rescate de un concepto arrinconado en su versión negativa, pero es justo preguntarse si tal esfuerzo es en último término útil. José Francisco García y Sergio Verdugo consideran que la respuesta es no: "la subsidiariedad no ha podido convertirse en un estándar que le entregue certeza a la comunidad jurídica" (224). Para concluir un juicio tan lapidario, los autores analizan fallos del Tribunal Constitucional donde el concepto de subsidiariedad ha sido relevante. Dicho análisis muestra de forma convincente que el principio de la subsidiariedad ha sido invocado tanto para proteger a particulares de la intromisión del Estado (por ejemplo, en el caso de la Ley de Prensa de 1995) como para permitir que el Estado obligue a particulares a garantizar el acceso a derechos constitucionalmente consagrados (por ejemplo, en los sucesivos fallos relativos al acceso a la salud y los planes de las Isapres). Esta ambivalencia desagrada a los autores, y a partir de ahí invitan a los defensores del principio de subsidiariedad a "condicionar su defensa a la aplicación práctica de una doctrina que hoy parece desvanecerse" (225). A mi parecer, el texto de García y Verdugo es el más político contingente de todos los artículos del libro y desde allí debe valorarse su riqueza. Los autores observan con sospecha que se haga un esfuerzo por recuperar un principio como el de subsidiariedad, porque no ven en él ninguna capacidad de impedir el avance de un progresismo jurídico refundacional centrado en la expansión de derechos sociales garantizados por el Estado, eventualmente, sobre la base de una nueva constitución. Opción que rechazan. Por eso, escriben: "El pragmatismo político no puede quedar olvidado en este punto, razón por la cual nuestro llamado es práctico: debiera buscarse la forma más eficaz de defender la sociedad de libertades bajo prismas comunes" (225). Volveré sobre este punto al final del texto.

Coincidiendo con los autores anteriores, Daniel Brieba se muestra escéptico respecto al alcance que puede tener el uso del concepto de subsidiariedad y de su utilidad para regular la vida en las sociedades modernas. Para Brieba, la subsidiariedad en sociedades que parten del reconocimiento de la autonomía individual para fijarse los fines de la propia vida y de la obligación del Estado a respetar los proyectos de 
vida particulares es un concepto útil pero subsidiario. Su problema fundamental, concluye Brieba, es que el principio estaría subespecificado y, por ende, sería operativamente dependiente de una concepción de la justicia que le provea "de los criterios de adecuación a ser satisfechos" (202). Escribe Brieba: "Al final, el principio de subsidiariedad es ante todo un criterio de presunción: nos dice que el peso de la prueba debe estar con los que en determinado caso quieren involucrar al Estado, y ése es su valor. En cambio, no nos dice que la provisión privada sea siempre mejor - y esa diferencia es bueno recordarla" (203).

Ahora bien, considerando que el principio de subsidiariedad reconoce esferas legítimas de acción tanto para el Estado como para las asociaciones voluntarias que las personas crean, no nos debe llamar la atención que pueda ser criticado por ser demasiado abierto y no entregar certeza jurídica. Por construcción, el principio de subsidiariedad no puede hacerlo. Tampoco me parece que sea una crítica insalvable que la subsidiariedad esté subespecificada de forma tal que "no es, en y por sí misma, una teoría comprensiva de justicia” (Brieba, 203). Nuevamente, al no tratarse de un principio mecánico (ver Mansuy), no puede exigirse a la subsidiariedad que entregue el tipo de universalidad que se le exigen a principios con pretensiones de universalidad. Dicho de otro modo, esas críticas al principio de subsidiariedad que se expresan en los capítulos de Brieba y de García y Verdugo son correctas, pero fuera de foco: la subsidiariedad no entrega lo que ellos esperan que entregue, pero no es menos cierto que tampoco pretendía hacerlo.

Otra crítica que parece ser más difícil de sortear para los defensores del principio de subsidiariedad es la referida a su origen religioso asociado principalmente a la doctrina social de la Iglesia. Como lo mencionan varios autores en sus respectivos artículos, el concepto tiene sus principales desarrollos dentro del pensamiento cristiano. La idea que las agrupaciones intermedias tienen espacios de soberanía propios se remonta al menos al teólogo calvinista Althusius en el siglo XVI, y en la tradición católica se consolidan con los escritos de Pio IX y León III en la segunda mitad del siglo XIX. La encíclica Rerum Novarum (1891) le da al concepto la formulación que rescatan varios de los autores del libro y que Pablo Ortúzar cita en el prólogo: "No es justo, según hemos dicho, que ni el individuo ni la familia sean absorbidos por el Estado; lo justo es dejar a cada uno la facultad de obrar con libertad hasta donde 
sea posible, sin daño del bien común y sin injuria de nadie. No obstante, los que gobiernan deberán atender a la defensa de la comunidad y de sus miembros" (Rerum Novarum, n. ${ }^{\circ} 48$, citado por Ortúzar, página 16). El origen religioso del concepto de subsidiariedad es mirado con sospecha por los principales críticos que escriben en el libro (García y Verdugo; Brieba). Al parecer, los autores adscriben a la idea que una sociedad que se moderniza necesariamente se seculariza. Una visión en línea con las concepciones del liberalismo decimonónico. Si es así, es comprensible que miren con recelo un concepto que ocupa un lugar tan central en una religión con tan alta presencia e influencia en Chile. Planteado desde esa óptica liberal, el desarrollo de un Estado laico parecería aconsejar el rechazo de conceptos de origen religioso; más aún si no ofrecen certeza jurídica (García y Verdugo) y están subespecificados (Brieba). No obstante, la idea que una sociedad moderna debe ser una sociedad secularizada fue derrotada por el hecho indesmentible de la multiculturalidad de la metrópoli contemporánea. Construir un Estado laico ya no es lo mismo que construir un Estado laicista y, por ende, así como las concepciones de tipo religioso no pueden aspirar a ser aceptadas sin escrutinio fuera de la comunidad de credo, el anticlericalismo es una concepción superada por el propio devenir de las sociedades globalizadas. Por lo tanto, la pertinencia del concepto de subsidiariedad debe ser evaluada con independencia de su origen religioso y en función de su capacidad para ayudarnos a comprender y organizar nuestros modos reales de vida.

Es en este punto donde Subsidiariedad ofrece dos textos de particular interés teórico. Por un lado, Aldo Mascareño trae a la mesa lo que, a mi juicio, es un marco sociológico adecuado para reflexionar sobre el diagnóstico de la crisis de confianza institucional (aunque expresado en un texto desproporcionado en extensión respecto del resto del libro). Si bien Chile tiene particularidades de las que debe hacerse cargo, cuentas impagas que cancelar y deudas históricas que resolver, no resulta convincente aislar la experiencia chilena de la crisis generalizada que enfrenta el orden social de los Estados-nación sobre los que están construidos los marcos institucionales que nos rigen. Construyendo un argumento desde la teoría sociológica de sistemas, Mascareño sostiene que si existiera un espacio para la intervención en los procesos de diferenciación de los sistemas, éste sería la contextualización: "En una socie- 
dad moderna que carece de un acuerdo fundante, queda la coordinación pragmática de rendimientos sistémicos como alternativa frente a las cegueras de la evolución y frente a las buenas intenciones". Y continúa: “... el desafío de la orientación sistémica contextual es captar las especificidades de cada sistema para, en su lenguaje, ofrecer las distinciones que la intervención busca introducir: mayor sensibilidad ecológica en la empresa, mayor sentido ético en los medios de comunicación, mayores condiciones de equidad en organizaciones, más conciencia solidaria en la esfera pública" (Mascareño, 227-228). La validación, o si se prefiere, la utilidad de los esfuerzos de contextualización se verifica ex post en función de sus capacidades reales de incidir en el funcionamiento del sistema y no a partir de una obligación o sometimiento que, desde una perspectiva de sistemas complejos, se torna cada vez más difícil. Las organizaciones intermedias son precisamente espacios donde tal contextualización puede producirse en los sistemas políticos. Desde una perspectiva sistémica, la búsqueda y reproducción del poder es lo que regula la dinámica de los sistemas políticos $\mathrm{y}$, por ende, otras consideraciones - éticas, culturales, de valoración de la integración social, la inclusión, la solidaridad, etcétera - son leídas y absorbidas por los sistemas políticos en la medida que regulen o no regulen la reproducción del poder. Pero esta forma de funcionar de la política (esta "lógica del poder") atenta inevitablemente contra la reproducción de bienes públicos que son fundamentales para la subsistencia de un sistema político. Una sociedad donde los ciudadanos no sostienen mínimos de reciprocidad y responsabilidad mutua está condenada a la profundización de la individuación y el desapego; y sobre esa creciente individuación, la práctica del acceso al poder pierde irremediablemente toda perspectiva ética. Una sociedad democrática que evoluciona bajo esa lógica se condena irremediablemente al debilitamiento de sus instituciones basales. Por eso, la existencia de espacios de soberanía en las organizaciones intermedias contribuye a regular la distribución del poder, impidiendo que ante la apatía y alejamiento de los ciudadanos de los espacios públicos (preocupados más de sus propias biografías que de la vida en común), estos queden capturados por grupos de interés específicos.

Desde una óptica diferente, Manfred Svensson ofrece argumentos complementarios. A juicio de Svensson, el concepto de subsidiariedad no sólo ofrece fundamentos que justifican el diseño de marcos insti- 
tucionales de tipo federalista o descentralizados; sino también posee la capacidad de contribuir a darle sostén a marcos institucionales que se hagan cargo del pluralismo contemporáneo bajo lo que denomina ordopluralismo. "Contra aquel prejuicio que ve las apelaciones a la subsidiariedad como parte de una agenda romántica a la cual subyacen visiones organicistas y pretensiones de armonía social algo ingenuas", indica Svensson, "[el ordopluralismo] invita a tener presente una triple pluralidad: estructural, cultural y direccional. Tener en mente los cruces de estos tres elementos no soluciona nuestros problemas prácticos, ni sugiere de modo evidente a qué tipos de soluciones arribará. Pero sí constituye un recordatorio de dimensiones de la vida humana que en un amplio abanico de problemas deben ser tenidas en cuenta y distinguidas" (Svensson, 94).

En suma, Subsidiariedad es una contribución que se agradece a nuestras estanterías. Invita a tomar una pausa en el debate sobre los tamaños del Estado y de los mercados recordándonos que en ese debate no podemos ignorar que las estructuras que nos damos para gobernar nuestra vida en común están incrustadas en nuestras relaciones sociales. Es un libro que logra capturar visiones contrapuestas respecto del concepto que los agrupa, dándole al lector herramientas suficientes para superar las simplificaciones que el concepto ha adquirido en el debate nacional. Es también un libro a ratos disparejo, algunos textos son extremadamente largos y otros terminan abruptamente cuando los argumentos recién se están desplegando. A mi juicio, al terminar la lectura de Subsidiariedad el lector no se retirará con una hipótesis que permita solucionar los desafíos que implica el diagnóstico de deterioro institucional que recorre Chile. Pese a todas sus virtudes, el concepto de subsidiariedad no ofrece y no puede ofrecer un mega relato de validez universal que calme la ansiedad de los espíritus libres por encontrar los cimientos que le permitan construir un orden o vínculo social. Y es quizás esa su gran virtud y su valor trascendente. Cuando García y Verdugo plantean en su artículo un llamado pragmático a abandonar el concepto de subsidiariedad para "defender la sociedad de libertades bajo prismas comunes" equivocan, a mi juicio, el camino. Nuestras libertades individuales son insostenibles desde concepciones de libertad negativa que reniegan o minimizan nuestro origen comunitario. Allí donde el humano olvida sus responsabilidades compartidas, los cimientos que 
permiten que las libertades individuales se desplieguen comienzan a horadarse. El ser autónomo que sólo ve y vela por el despliegue de su propia individualidad termina usufructuando de los bienes públicos que permiten que esa libertad exista, pero no los alimenta, no los cuida. Las democracias liberales que se conciben a sí mismas como mero diseños contractuales entre individuos autónomos son, a mi entender, incapaces de defenderse de sus propias contradicciones y terminan, tarde o temprano, vaciando los espacios públicos de significados. El poder, como medio generalizado de intercambio de los sistemas políticos, se reproduce en ellas alejada de los ciudadanos y estos, a su vez, se alejan entre sí. En ese contexto, las condiciones que llevan a la desconfianza y deslegitimización de las instituciones siguen un lento pero progresivo deterioro. Nada de eso lo puede impedir el concepto de subsidiariedad por derecho propio. No puede porque la subsidiariedad no es una receta, sino que el llamado de atención que las propias sociedades hacen al observar cómo se construyen castillos en el aire. El rescate del concepto de subsidiariedad es siempre una advertencia a la urgencia del problema. Al hablar de subsidiariedad, escribe Pablo Ortúzar, "algo que no puede dejar de mencionarse [...] es el vínculo que ella tiene con determinados momentos históricos [...]. No es casualidad que sus desarrollos estén vinculados, según sea el momento, a la lucha contra el absolutismo y la intolerancia religiosa en el contexto de la reforma protestante, a las advertencias contra las pretensiones totalizantes del mercado y del Estado a fines del siglo XIX, a la lucha contra los totalitarismos en el siglo XX y, finalmente, a la pretensión de los Estados de bienestar y del liberalismo economicista de lograr soluciones despersonalizadas a los desafíos de la vida en común en el siglo XXI" (23-24). Tiene razón Ortúzar. En nuestros tiempos, esos riesgos van asociados a la expansión de una visión dogmática de la autonomía individual reducida a mero individualismo. Es un riesgo real impulsado por la globalización y el desacople de todos los sistemas (económicos, políticos, comunicacionales, culturales) en los que los humanos se desenvuelven. Nuestro riesgo es que en la época de mayor interdependencia que ha conocido la experiencia humana, los humanos nos creamos realmente esa ilusión que existimos desde antes del encuentro con otros e ignoremos que somos seres sociales de origen. Subsidiariedad es un libro que nos recuerda ese eslabón olvidado desde donde venimos. EP 